\title{
Synthesis of Indole Annulated Benzazepine Derivative of Medicinal Interest
}

\author{
ADITI VANDANA, YOGITA YADAV and D. KISHORE \\ Department of Chemistry,Banasthali University,Banasthali - 304022 (India) \\ ${ }^{*}$ Corresponding author E-mail: adianand86@ gmail.com \\ http://dx.doi.org/10.13005/ojc/290451
}

(Received: September 25, 2013; Accepted: November 11, 2013)

\begin{abstract}
The ubiquity of benzazepines in medicinal chemistry is undoubtedly a consequence of the multifarious biological response which they elicit in combating a variety of body ailments.A benzazepine derivative-'Fenoldopam mesylate'has emerged as avasodilator in peripheral arteries ansd as a diuretic in the kidneys. This discovery provided an optimism for the search of other novel agents from benzazepine class of compounds which could show a higher level of medicinal efficacy. The proposed synthesis (scheme-1), in its first step was propelled forward with the formation of compound 1.3(which resulted from the reaction of succinyl chloride and $\mathrm{p}$-fluoroaniline). The reaction of 1.3 with ethyl formate in the presence of a base formed 1.4 which underwent Japp-Klingemann reaction with aryl diazonium chloride followed by cyclocondensation with acid under the conditions of Fischer indolization to give indole substituted derivative 1.5.
\end{abstract}

Key words: P-fluoroaniline,Sunninyl chloride,Japp-Klingemann reaction, Fischer Indolization,Spectral study.

\section{INTRODUCTION}

Benzazepine moiety occurs frequently in both natural and synthetic drugs and is of highly biological interest. The use of this class of compound is not merely confined to the management of stress related conditions and for their use as antibacterial agents $^{1,3}$, but their additional applications are continuously emerging.Galantamine(Galanthamine), a benzazepine derived from norbelladine, has been studied in the treatment for Alzheimer disease ${ }^{4}$. In a quest to develop easily accessible routes to the synthesis of some novel heteroring annulated benzazepine derivatives, the present investigation aims to examine the operational feasibility of the proposed strategy outlined in scheme- 1 for thesynthesis of compounds I.6-1.7.

\section{MATERIALS AND METHOD}

P-fluoroaniline and succinyl chloride were the product of Fischer Scientific.All the chemicals employed for synthesis were of analytical grade and were used as supplied without further purification. All the solvents were dried and distilled before use. Melting points were determined in open glass capillaries and are uncorrected. The purity of the compounds was checked by TLC on silica gel(G) plates.The visualization of spot was carried in an iodine chamber. IR spectra were recorded on 
CE(SHIMADZU)FTIR-8400S.1 H NMR spectra were recorded on model AC-300F(Brucker) using CDCl3/DMSO-d6 as solvent and TMS as an internal reference.Chemical shift are expressed in $\delta \mathrm{ppm}$.

Synthesis of (7-fluoro-3,4-dihydro-1H-benzo[b] azepine-2,5-dione) (compound-1.3) Acylation

Compound $1.1(2.20 \mathrm{~g})$ was mixed with succinyl chloride $1.2(1.64 \mathrm{~g})$ and dry pyridine $(5 \mathrm{ml})$. The mixture was refluxed for 10-15 mins.Cooled reaction mixture was poured slowly with stirring in 150-200ml ice cold water.The resulting solid reactant which was settled was filtered, washed with cold water, recrysstalized from hot water containing few drops of methanol.

\section{Friedel craft reaction}

Compound above prepared(2.58 g)was mixed with PPA $(5 \mathrm{~g})$ and heated at $150-160^{\circ} \mathrm{C}$ for $4 \mathrm{hr}$ (the process of the reaction was monitored by TLC). The reaction mixture was cooled to $20^{\circ} \mathrm{Cand}$ concenterated salt of $\mathrm{Na}_{2} \mathrm{CO}_{3}$ was added to make it alkaline. The product was extracted with ethyl acetate $(3 \times 10 \mathrm{ml})$. The extract was dried overNa $\mathrm{SO}_{4}$ and concenterated in vaccum. The residue was purified by column chromatography of silica gel with $\mathrm{CHCl}_{3}$ as an eluent to give compound 1.3.yield60\%,m.p.120-122 ${ }^{\circ} \mathrm{C}$.

Synthesis of 4-(ethoxymethylene)-7-fluoro3,4-dihydro-1H-benzo[b]azepine-2,5-dione (compound-1.4)

To a solution of $10 \%$ sodium ethoxide $(10 \mathrm{ml})$ in benzene $(50 \mathrm{ml})$ at $00 \mathrm{C}$, a solution of ethyl formate $(10 \mathrm{mml})$ in dry benzene $(25 \mathrm{ml})$ was added. To this mixture compound $1.3(2.25 \mathrm{~g})$ in benzene $(25 \mathrm{ml})$ was added. The mixture was stirred for $4 \mathrm{hrs}$ at room temperature and allowed to stand overnight.It was then diluted with cold water, acidified with dil. $\mathrm{HCl}$ and extracted with ether. The solvent was evaporated and the resultant compound (1.4) was recrystallised from ethanol to give pure compound 1.4.yield $50 \%$, m.p.298-300oC.

Synthesis of 8-fluorobenzo[6,7]azepino[4,3-b] indole-6,12(5H,1H)-dione (compound-1.5) Preparation of hydrazone

A solution of Compound1.4a (3.26) was kept aside for 10 minutes. It was then added portionwise to an ice cold mixture containing compound 1.4 $(4.0 \mathrm{ml})$, sodium acetate $(6 \mathrm{~g})$, methanol $(37.0 \mathrm{ml})$ and water $(20.0 \mathrm{ml})$ over a period of 0.5 hours with stirring. The contents were allowed to stand for further 0.5 hours and the resulting solid mass was filtered, washed with water, dried and crystallized from ethanol.

\section{Cyclization of hydrazone}

A solution of hydrazone above prepared $(3.18 \mathrm{~g})$ in a mixture of acetic $\operatorname{acid}(19.0 \mathrm{ml})$ and hydrochloric acid $(4.7 \mathrm{ml})$ was refluxed on an oil-bath preheated to $125-130^{\circ} \mathrm{C}$ for 0.5 hours. The contents were then cooled and poured into cold water with stirring. The separated brown solidwas purified by passing through a column of silica gel using $50 \%$ benzene in petroleum ether as eluent.yield $66 \%$,m.p. $133-135^{\circ} \mathrm{C}$.

\section{RESULTS AND DISCUSSION}

Scheme - 1 envisaged that the reaction of 1.3 with ethyl formate in presence of a base formed 1.4 which undergo Japp-Klingemann reaction with aryl diazonium chloride followed by cyclocondensation with acid under the conditions of Fischer indolization to give indole ring substituted derivative 1.5

\section{IR spectra}

Infrared spectra of compound 1.3 on $\mathrm{KBr}$ pellet exhibited strong absorption bands at $1660 \mathrm{~cm}$ and $1700 \mathrm{~cm}$ - for the carbonyl group of $\mathrm{CONH}$ and $\mathrm{CO}$ groups respectively,along with this IR spectum also exhibited bands at $3400 \mathrm{~cm}^{-}(\mathrm{NH}),\left[2970,1430 \mathrm{~cm}^{-}\right.$ $\left(\mathrm{CH}_{2}\right.$ next to $\left.\left.\mathrm{C}=\mathrm{O}\right)\right], 2970 \mathrm{~cm}^{-}(\mathrm{C}-\mathrm{H}), 1590 \mathrm{~cm}^{-}(\mathrm{C}=\mathrm{C})$.

Infrared spectra of compound 1.4 on $\mathrm{KBr}$ pellet exhibited peaks at $3068 \mathrm{~cm}-(\mathrm{C}-\mathrm{H}$ str. of $\mathrm{C} 6 \mathrm{H} 5 \mathrm{~F}), 1550 \mathrm{~cm}^{-}(\mathrm{C}=\mathrm{C}$ str. of $\mathrm{C} 6 \mathrm{H} 5 \mathrm{~F}), 3280 \mathrm{~cm}^{-}(\mathrm{NH}$ str.) $[\mathrm{CONH}], 1680 \mathrm{~cm}^{-}(\mathrm{C}=\mathrm{O})[\mathrm{CONH}], 1610 \mathrm{~cm}^{-}(\mathrm{C}=\mathrm{O}$ str.), $1620 \mathrm{~cm}^{-}(\mathrm{C}=\mathrm{C})$.

Infrared spectra of compound 1.5 on $\mathrm{KBr}$ pellet exhibited peaks $3068 \mathrm{~cm}-(\mathrm{C}-\mathrm{H}$ str. of $\mathrm{C} 6 \mathrm{H} 5 \mathrm{~F})$, $1550 \mathrm{~cm}^{-}\left(\mathrm{C}=\mathrm{C}\right.$ str. of $\left.\mathrm{C}_{6} \mathrm{H}_{5} \mathrm{~F}\right), 3280 \mathrm{~cm}-(\mathrm{NH}$ str. $)$ $[\mathrm{CONH}], 1680 \mathrm{~cm}^{-}(\mathrm{C}=\mathrm{O})[\mathrm{CONH}], 1610 \mathrm{~cm}-(\mathrm{C}=\mathrm{O}$ str.), $3300 \mathrm{~cm}-(\mathrm{NH}$ sec.amine). The formation of compound 1.5 was confirmed by appearance of peak at $3300 \mathrm{~cm}-$ ( $\mathrm{NH}$ of indole ring) . 


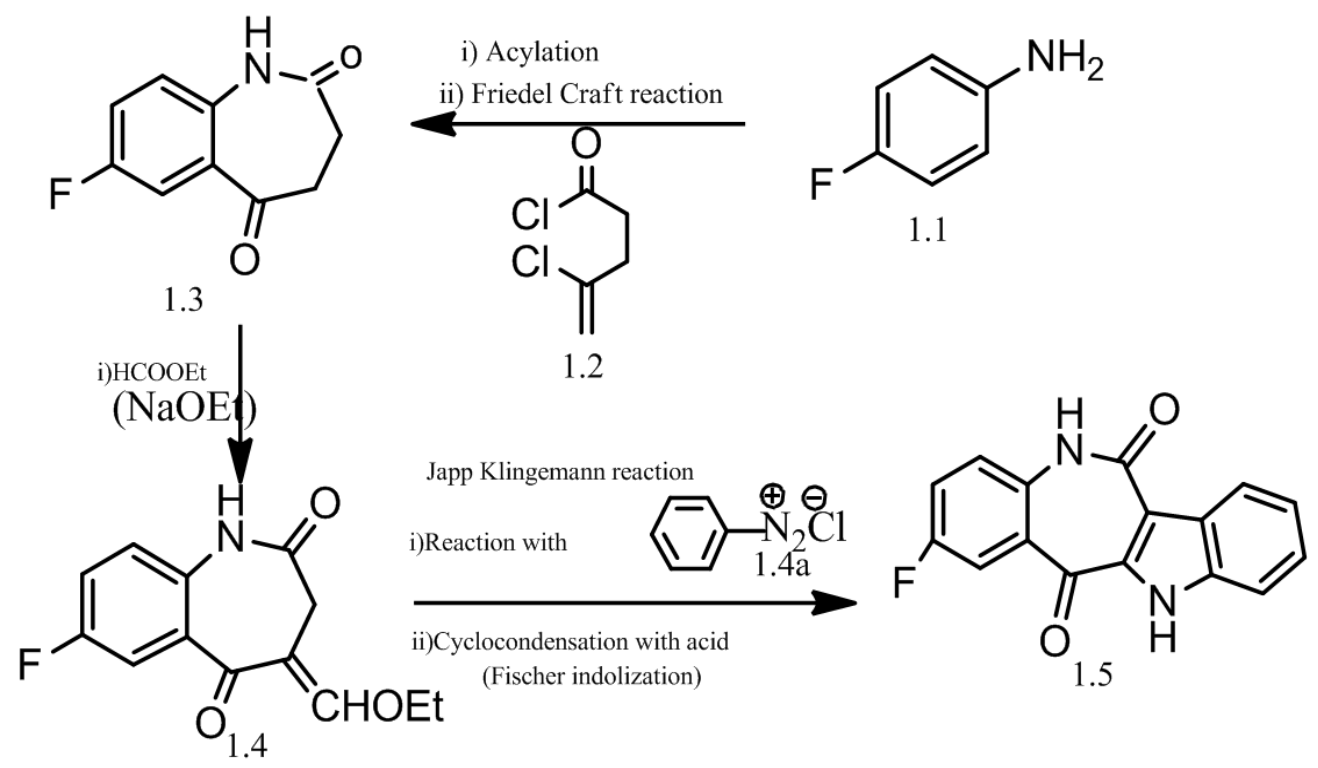

\section{Scheme 1:}

\section{H NMR spectra}

$1 \mathrm{H}$ NMR spectrum of compound 1.3 in $\mathrm{CDCl}^{3+} \mathrm{DMSO}-\mathrm{d} 6$ displayed signals for the presence of 8 protons.Appearence a downfield broad singlet for $1 \mathrm{H}$ at $\delta 8.0$ was attributed to $\mathrm{NH}$ group. Appearence of multiplet at $\delta 7.40-7.87$ wasassigned to the three protons of fluorobenzene ring.A singlet for four protons which appeared at $\delta 2.93$ and $\delta 2.42$ was attributed to two $\mathrm{CH} 2$ groups of azepanedione ring.

1H NMR spectrum of 1.4 in $\mathrm{CDCl}_{3}+\mathrm{DMSO}^{-}$ d6 exhibited a downfield broad singlet for $1 \mathrm{H}$ at $\delta 8.0$ which was attributed to $\mathrm{NH}$ group of azepanedione ring.Another singlet for $1 \mathrm{H}$ at $\delta 6.95$ was assigned to the protons of $\mathrm{CH}$ group attached to ether group on one side and $\alpha, \beta$-unsaturated carbonyl group on other side.Presence of a triplet for $3 \mathrm{H}$ at $\delta 1.21$ and quartet for $2 \mathrm{H}$ at $\delta 4.49$ were assigned to the ethyl group of enolic ether. .Appearence of multiplet at $\delta 7.45-7.98$ wasassigned to the three protons of fluorobenzene ring. A singletfor two protonswhich appeared at $\delta 2.90$ was attributed to $\mathrm{CH} 2$ group of azepanedione ring.

$1 \mathrm{H} \mathrm{NMR}$ spectrum of 1.5 in $\mathrm{CDCl}_{3}+\mathrm{DMSO}-$ d6 exhibited a downfield broad singlet for $1 \mathrm{H}$ at $\delta 8.0$ which was attributed to $\mathrm{NH}$ group of azepanedione ring..Appearence of multiplet at $\delta$ 7.45-7.98 wasassigned to the three protons of fluorobenzene ring. .Another singlet for $1 \mathrm{H}$ at $\delta 11.63$ was assigned to $\mathrm{NH}$ group of indole. Appearence of multiplet at $\delta$ 6.91-8.47wasassigned to the four protons of benzene ring .

\section{Mass spectra}

Mass spectrum of compound 1.3 gave peaks at $\mathrm{m} / \mathrm{z} 193.05(100.0 \%), 194.06(11.0 \%)$ which provided a strong evidence to its molecular weight(193.17).

Mass spectrum of compound 1.4 gave peaks at $\mathrm{m} / \mathrm{z} 249.08(100.0 \%), 250.08(14.5 \%)$ which provided a strong evidence to its molecular weight(249.24).

Mass spectrum of compound 1.5 gave peaks at $\mathrm{m} / \mathrm{z} 310.32(100.0 \%), 218.363(15.5 \%), 239$ $.99(11.1 \%), 279.552(9.8 \%), 291.112(5.4 \%)$ provided strong evidence to its molecular weight(310.32).

\section{ACKNOWLEDGEMENTS}

Authors are thankful to the university authorities for providing laboratory facilities. 


\section{REFERENCES}

1. Johnson P.D., Aristoff P.A., Zurenko G.E., Schaadt R.D., Yagi B.H.,Ford C.W., Hamel J.C., Stapert D., Moerman J.K., Synthesis and Biological Evaluation of Benzazepine Oxazolidinone Antibacterials, Bioorg. Med. Chem. Lett ., 13: 4197-4200 (2003).

2. Bal Krishan, Om Prakash and E. H. ElMossalamy., Orient. J. Chem., 29(1): 381-388 (2013)

3. Das J., Sitaram Kumar M., Subrahmanyam
D., Sastry T.V., Prasad Narasimhulu C.,Laxman Rao C.V., Kannan M., Roshaiah M.,Awasthi R.,Patil S..N.,Sarnaik H.M., Rao Mamidi,Selvakumar N.V., Iqbal J., Substituent Activity Relationship Studies on New Azolo Benzoxazepinyl Oxazolidinones, Bioorg. Med. Chem., Lett., 14(23): 8032-42 (2006).

4. Olin J.,Schneider L., Galantamine for Alzheimer's Disease, Cochrane Database Syst Rev. CD001747,3 (2002). 